\title{
REFLEXO DA CONSTITUCIONALIZAÇÃO NAS RELAÇÕES PRIVADAS: A EFICÁCIA HORIZONTAL DOS DIREITOS FUNDAMENTAIS
}

\section{CONSTITUCIONALIZATION'S REFLEX IN PRIVATE RELATIONS: THE HORIZONTAL EFFECTIVENESS OF FUNDAMENTAL RIGHTS}

\author{
${ }^{1}$ Cristina Paiva Serafim Gadelha Campos \\ ${ }^{2}$ José Rodolpho Régis Queiroz
}

\section{RESUMO}

A irradiação dos efeitos dos valores e princípios da Constituição de um Estado pelo ordenamento jurídico a ela respectivo se traduz no processo de constitucionalização, o qual encontra espaço consolidado nos sistemas jurídicos contemporâneos. Sendo assim, o presente artigo científico busca demonstrar que um dos principais aspectos do referido processo se trata da aplicação dos direitos fundamentais nas relações privadas. Neste sentido, utilizará a pesquisa bibliográfica e o método indutivo para constatar a influência dos ditames constitucionais sobre as relações sociais, dentre as quais se incluem as relações privadas, verificando que a proteção que a Constituição procura dar aos direitos fundamentais suscita sua observância nas relações entre particulares.

Palavras-chave: Irradiação de efeitos, Valores e princípios da constituição, Constitucionalização, Direitos fundamentais, Relações privadas, Eficácia horizontal

\begin{abstract}
Irradiation of the effects of the values and principles of the Constitution of a State by the law to her respective translates into the constitutional process, which is consolidated space in contemporary legal systems. Thus, this research paper seeks to show that one of the main aspects of this process it comes to the application of fundamental rights in private affairs. To this end, use the literature and the inductive method to verify the influence of constitutional principles on social relations, among which include the private relationships, checking that the protection that the Constitution seeks to give fundamental rights raises its observance in relations between privates.
\end{abstract}

Keywords: Irradiation effects, Values and principles of the constitution, Constitutionalisation, Fundamental rights, Private relationships, Horizontal effectiveness

\footnotetext{
${ }^{1}$ Mestrando em Direito pelo Centro Universitário de João Pessoa - UNIPÊ, Paraíba, (Brasil). Tem Experiência na Àrea das Ciências Sociais Aplicadas, com Ênfase em Direito. E-mail: tutortreinamento@gmail.com

${ }^{2}$ Mestranda em Direito pelo Centro Universitário de João Pessoa - UNIPÊ, Paraíba, (Brasil). E-mail: tutortreinamento@gmail.com
} 


\section{INTRODUÇÃO}

O processo de constitucionalização do direito tem se desenvolvido com grande força nos sistemas jurídicos hodiernos. Os valores e princípios das Constituições dos Estados têm recebido significativa importância por parte dos legisladores, intérpretes e aplicadores do direito, o que demonstra que os efeitos dos documentos constitucionais estão sendo irradiados cada vez com mais vigor pelos ordenamentos jurídicos respectivos, lhes dando fundamento e validade.

Neste sentido, merece destaque a irradiação dos valores das constituições no que tange às normas de direitos fundamentais que preveem. Percebe-se que as diversas cartas constitucionais mundiais conferem significativa importância e respeito aos direitos fundamentais, cada qual os tendo consagrado de acordo com a realidade social que deve regular, considerando sobretudo os anseios e necessidades de seus cidadãos. Sendo assim, destaca-se que a introdução de tais direitos na norma jurídica de maior valor para o país foi resultado de um cauteloso processo de verificação da realidade do Estado, bem como dos direitos adequados à garantia do bem estar dos regidos.

Destarte, o respeito aos direitos fundamentais nas relações reguladas por quaisquer dos ramos do direito se mostra imprescindível. Tamanho é o valor que as constituições contemporâneas dispensam aos direitos fundamentais que não restam dúvidas de que a aplicação destes direitos nas relações jurídicas é uma das principais vontades dos legisladores constituintes.

Considerando que as relações que envolvem apenas sujeitos privados têm se destacado como as que oferecem maiores riscos aos particulares, são nelas que seus direitos fundamentais estão sendo mais ameaçados. Sendo assim, eis um campo que deixa evidente a necessidade de receber a irradiação dos valores constitucionais, especialmente os que protegem a esfera individual do homem.

Em outras palavras, a constitucionalização exerce um importante papel nas relações privadas. A irradiação dos ditames constitucionais sobre as relações horizontais é um argumento de peso para demonstrar que também entre sujeitos privados deve reinar o respeito e a garantia aos direitos fundamentais.

Destarte, utilizando a pesquisa bibliográfica e o método indutivo, este artigo científico busca demonstrar o quanto o processo de constitucionalização contribui para a consciência de que as relações privadas são campos propícios à aplicação dos direitos fundamentais, e com bastante razão. Além disso, a análise da experiência de outros países 
com a eficácia horizontal destes direitos, notadamente a alemã e a norte americana, será trazida ao longo deste estudo, como forma de ratificar a necessidade de garantir a proteção dos direitos fundamentais do homem, em suas relações privadas.

\section{PROCESSO DE CONSTITUCIONALIZAÇÃO DO DIREITO}

A constitucionalização do direito é um importante instrumento de uniformização dos diversos ramos jurídicos, tomando por base os ditames constitucionais. Destacando que a constitucionalização é um processo multifacetado, Teixeira $(2008$, p. 47) afirma que se trata de "um marco inicial daquilo que será a pauta de conduta político-jurídica que todos - seja o Estado ou os indivíduos - deverão se guiar: o Estado de Direito”.

Considerando sua potencialidade para irradiar a essência da constituição de um país por todo o ordenamento jurídico deste, é um mecanismo eficaz para garantir que as fontes jurídicas de um Estado - quaisquer que sejam e independentemente do ramo do direito ao qual estejam vinculadas - comunguem das mesmas diretrizes, notadamente as consagradas na sua Carta Magna.

Eis que a falta de comunicação entre os ramos do direito pode acarretar efeitos indesejáveis, tendo em vista que de cada um deles poderiam emanar normas e interpretações que seguissem orientações somente por eles adotadas, e que muito provavelmente conflitariam com as orientações seguidas por outros ramos. Além dessa falta de uniformidade, a ausência de comunicação entre as searas do direito impede que um determinado campo jurídico aproveite os estudos desenvolvidos por outro campo, especialmente acerca de disciplinas jurídicas já pacificadas (SILVA, 2005, p. 17).

A consciência de que o documento constitucional escrito ocupa o topo do ordenamento jurídico de um país contribui significativamente para eliminar esses problemas de comunicação. Tendo em vista que a constituição de um Estado é a norma que figura no ápice de um sistema hierarquizado de fontes jurídicas, e da qual devem emanar os fundamentos para quaisquer delas que venham a serem produzidas e vigorar neste país, a subordinação de todo o ordenamento jurídico à constituição deságua na uniformização dos diversos ramos que o compõem.

Como norma de maior valor normativo de um ordenamento jurídico, a constituição de um país está dotada de valores que devem ser respeitados por quaisquer outras fontes jurídicas que venham a fazer parte do mesmo ordenamento. Para que um determinado sistema normativo se mantenha uniforme e esteja assentado nas mesmas diretrizes, é imprescindível 
que os ditames do documento constitucional escrito a ele relacionado subordinem quaisquer outras normas do sistema, neles encontrando seus fundamentos de validade.

Contudo, a supremacia constitucional ou a força normativa da constituição, ainda que façam parte do processo de constitucionalização do direito, não significam a mesma coisa que este fenômeno (SILVA, 2005, p. 17-18). Na realidade, a constitucionalização do direito diz respeito à irradiação dos efeitos das normas e valores constitucionais sobre os demais ramos do direito.

Seja qual for a seara jurídica enfocada - não importando se está se levando em consideração seu conjunto legislativo ou suas orientações doutrinárias e jurisprudenciais -, é facilmente perceptível a influência dos ditames constitucionais sobre todo o ordenamento jurídico a eles relacionado. A Constituição de um Estado é, portanto, a fonte dos valores que nortearão todos os ramos do direito, embasando sua estruturação e funcionamento.

Em decorrência dessa irradiação dos efeitos dos valores constitucionais por todo o ordenamento jurídico, é possível observar uma outra expressão da constitucionalização do direito: a introdução no plano constitucional de institutos e regras que antes faziam parte do plano infraconstitucional (QUEIROZ; MAGALHÃES, 2014).

Sem dúvidas, trata-se de expressão de menor relevância deste fenômeno, tendo em vista que é uma consequência natural da expansão dos ditames constitucionais sobre os demais ramos do direito que, após assimilarem os princípios que embasam o documento constitucional, repercutiram nas relações sociais com tamanho impacto que acabaram por terem alguns de seus preceitos inseridos na constituição. Neste caso, o constituinte percebeu que o interesse público que detinham esses institutos os faziam merecer ampla proteção, notadamente a constitucional.

Neste sentido, percebe-se que o conceito de constituição como ordenamento da sociedade como um todo, e não somente estatal, foi decisivo para garantir a irradiação dos valores e princípios constitucionais. Nas palavras de Hesse (1992, p. 16), tal fator se traduz na consideração da constituição também como "ordem jurídico-fundamental da comunidade", substituindo a antiga visão, que se limitava a considerá-la ordem jurídico-fundamental exclusivamente do Estado.

Entretanto, também há que se considerar que em países marcados por tradições dogmáticas com grande significado, maior será a dificuldade para modificar suas estruturas dogmáticas consolidadas (SCHUPPERT; BUMKE, 2000, p. 38). Exemplo disso é o que ocorre na Alemanha, onde se percebe grande resistência dos civilistas à aceitação da constitucionalização do ordenamento jurídico como um todo. 
Quanto ao direito brasileiro, exemplos de manifestações da difusão da referida expressão do processo de constitucionalização no direito brasileiro são percebidos pelo acolhimento, pela Constituição Federal de 1988, de normas que frequentemente são utilizadas para regular as relações sociais, e que originariamente fazem parte da legislação infraconstitucional (QUEIROZ; MAGALHÃES, 2014). São os casos das normas de direitos fundamentais conferindo proteção aos direitos autorais e de herança, bem como das disposições que garantem a impenhorabilidade da pequena propriedade rural e a dissolução do casamento através do divórcio.

Sendo assim, percebe-se que o processo de constitucionalização do direito se traduz no efeito expansivo das normas constitucionais, refletindo na irradiação de seu conteúdo material e axiológico por todo o sistema jurídico. Como decorrência, a validade e o sentido do conjunto de fontes jurídicas que compõem o plano infraconstitucional fica condicionado à compatibilidade com os valores, fins públicos e comportamentos consagrados pela constituição.

Considerando que a constituição de um Estado tem a importante atribuição de estruturá-lo, especialmente ao traçar as diretrizes que orientarão o funcionamento dos poderes públicos, percebe-se que a constitucionalização repercute diretamente nas relações entre os setores público e privado. Além disso, uma análise mais cuidadosa permite constatar que ao estruturar os três Poderes constituídos, as normas constitucionais - através da irradiação de seus efeitos sobre os demais ramos do direito - também refletem nas relações entre particulares (BARROSO, 2005).

Neste sentido, destaca Leonel:

Depois de constatada a incidência, algumas premissas se formam. A primeira é que a extensão e intensidade do efeito de irradiação dos direitos fundamentais é algo, em si, indeterminado, apesar de necessitar de fundamentação específica em cada caso. Essa irradiação não se limitaria, no entanto, nem à legislatura e nem à jurisprudência, mas a todas as funções estatais. (2014, p. 11)

Observe-se, pois, a atuação do Poder Legislativo, o qual pode ser identificado como um poder público cuja função precípua é legislar, traduzindo em normas escritas a vontade do povo, e por isso mesmo garantindo-lhe maior proteção. Como decorrência do processo de constitucionalização, a discricionariedade daqueles que dão concretude ao Legislativo passa a ser limitada, tendo em vista que os legisladores constitucional e infraconstitucional devem pautar suas atuações na conformidade com as diretrizes que baseiam a Carta Magna do Estado, as quais, por sua vez, necessariamente devem corresponder à realidade do país e aos 
anseios dos regidos. Além disso, a constitucionalização também impõe ao legislador deveres de atuação, com vistas a realizar os direitos e programas constitucionais, adequando-os à realidade social (MIRANDA, 2000).

Quanto ao Poder Executivo, também se percebe que sofre influência da constitucionalização do direito, tanto nas relações entre a Administração Pública e os particulares, quanto nas relações que envolvem somente particulares - enquanto administrados e participantes do processo de escolha dos governantes, bem como de sujeitos para os quais devem estar voltadas as atuações dos representantes do povo.

Sendo assim, além de igualmente terem sua discricionariedade limitada e deveres de atuação, como decorrências da irradiação dos valores constitucionais sob o ordenamento jurídico, os responsáveis pelo Executivo encontram na constitucionalização fundamento para praticar atos de aplicação direta e imediata da constituição, sem dependência da interposição do legislador infraconstitucional.

Em relação ao Poder Judiciário, bastante nítida é a influência da constitucionalização sobre seu funcionamento. Tendo em vista sua responsabilidade de exercer o controle de constitucionalidade das leis, a irradiação dos valores constitucionais lhe impõe parâmetros para desempenhar o controle incidental, ou mesmo por ação direta. Além disso, como decorrência natural, a interpretação que venha a fazer de todas as normas que componham o sistema jurídico fica condicionada aos valores constitucionais, sob pena de falta de validação.

Não obstante a facilidade para a percepção dos efeitos da constitucionalização do direito sobre os poderes públicos e suas relações com os particulares, também são bastante visíveis as implicações deste processo sobre as relações que não envolvem participação estatal, mas somente sujeitos particulares. Nesta esfera das relações privadas, percebe-se que a constitucionalização limita a autonomia da vontade, impondo limites à liberdade de contratar e ao uso da propriedade, de modo a subordinar a atuação privada aos valores constitucionais e aos direitos fundamentais (BARROSO, 2005).

Sendo assim, constata-se que o processo de constitucionalização do direito é um importante mecanismo de uniformização do sistema jurídico, com base nos ditames constitucionais. Além disso, pode ser considerado um instrumento eficaz para contribuir com a concretização dos anseios sociais, tendo em vista que a Carta Magna de um país deve tê-los como base e principal objetivo, e ainda considerando que o alcance da constitucionalização é bastante amplo, repercutindo na atuação dos poderes públicos e nas manifestações particulares. 


\section{CONSTITUCIONALIZAÇÃO E APLICAÇÃO DE DIREITOS FUNDAMENTAIS NAS RELAÇÕES JURÍDICAS}

O processo de constitucionalização, que como acima esclarecido, pode ser entendido como a irradiação dos efeitos das normas e valores constitucionais aos outros ramos do direito, favorece o debate acerca do conteúdo normativo que está sendo irradiado. Alimentando questionamentos relativos à influência dos ditames constitucionais nas variadas relações sociais reguladas pelo direito, intensifica-se o debate especialmente acerca da aplicação dos direitos fundamentais nas relações jurídicas.

O documento constitucional é o instrumento por meio do qual, além de organizar a estrutura do Estado, a forma de governo e o modo de aquisição e exercício do poder político, são garantidas liberdades públicas aos cidadãos (MIRANDA, 2000). Destarte, a Carta Magna pode ser vista como o documento que, entre outros objetivos, visa garantir que os regidos possam desfrutar de direitos e garantias fundamentais.

Sendo assim, tendo os efeitos de suas normas e valores irradiados, irradiada também será a certeza de que as relações jurídicas serão campo propício à concretização dos direitos fundamentais. Isso ocorre pois estes são importantes elementos da constituição, verdadeiras diretrizes desta, uma vez que fazem parte de sua essência.

Portanto, nada mais natural que todas as relações que venham a fazer parte do ordenamento jurídico - cujo fundamento de validade é constitucional - respeitem os direitos e garantias fundamentais. O alcance de tais direitos e garantias deve ser o mais amplo possível, tal como é a amplitude do processo de constitucionalização, o que implica dizer que devem participar de quaisquer relações jurídicas.

Partindo para a análise das relações que merecem regulação por meio do direito, percebe-se que algumas são marcadas pela posição de igualdade entre os sujeitos envolvidos, enquanto outras se caracterizam pela existência de hierarquia entre as partes, uma vez que os interesses que uma defende são mais relevantes que os defendidos pela outra (SILVA, 2005). De acordo com o grau de hierarquia que possa existir nas relações jurídicas, fala-se em eficácia horizontal dos direitos fundamentais e em eficácia vertical dos direitos fundamentais.

A eficácia horizontal dos direitos fundamentais diz respeito à aplicação de direitos fundamentais em relações sociais onde as partes estão situadas no mesmo plano, ou seja, em relações onde nenhuma das partes envolvidas ocupa posição de superioridade em relação à outra. A marca característica de tais situações é a igualdade, tendo em vista que é possível constatar a ausência de hierarquia e subordinação entre os sujeitos envolvidos. 
Sendo assim, considerando que os pactos que envolvem somente particulares são caracterizados pelo idêntico valor conferido às partes que compõem o seu elemento subjetivo, percebe-se que as relações entre particulares são os espaços ideais para a concretização da eficácia horizontal dos direitos fundamentais.

Por outro lado, as relações que vinculam particulares e o Estado são marcadas por partes que não se situam em uma mesma posição hierárquica, tendo em vista que os interesses públicos se sobrepõem aos interesses particulares. Nestes casos, são firmadas relações verticais, tendo em vista que o Estado, representando os interesses públicos, ocupa o ponto mais alto e os particulares figuram no ponto mais baixo, representando seus anseios privados.

Considerando relações verticais, a eficácia que os direitos fundamentais nelas terão também será vertical. Esta é uma decorrência da própria estrutura de tais relações, tendo em vista que a verticalidade é sua característica marcante (DURIG, 2012).

Todavia, ainda que as relações sejam horizontais ou verticais, a incidência de direitos fundamentais não ocorrerá de maneiras diferentes. Por estarem inseridas em um ordenamento jurídico que encontra nos ditames constitucionais seu fundamento de validade, tais relações receberão igualmente a irradiação dos efeitos dos valores da constituição, e de acordo com eles devem estar constituídas.

Ratificando esta ideia, Tepedino (2002, p. 364) salienta que a verdade é que "não há negócio jurídico ou espaço de liberdade privada que não tenha o seu conteúdo redesenhado pelo texto constitucional". Destarte, entre outras diretrizes que deverão observar, necessariamente devem garantir que os direitos fundamentais estarão sendo respeitados.

Considerando o conteúdo das disposições normativas que os garantem, a única diferença constatada quanto à sua aplicação é que alguns direitos fundamentais foram consagrados constitucionalmente para serem concretizados perante particulares, enquanto outros necessariamente deverão ter o Estado como sujeito passivo. Como destaca Mendes, Coelho e Branco (2010), os direitos trabalhistas, entre outros direitos sociais, têm eficácia direta contra empregadores privados. Além disso, a previsão do direito de resposta proporcional ao agravo, contida no art. $5^{\circ}, \mathrm{V}$, da Constituição Federal de 1988, terá como sujeito passivo o órgão de imprensa particular que deu causa ao agravo.

Por outro lado, os que precisarem de assistência judiciária gratuita e comprovarem insuficiência de recursos, o Estado lhes prestará assistência gratuita integral, evidenciando que este direito fundamental somente poderá tê-lo como sujeito passivo, em conformidade com o art. 5, LXXIV, da Carta Magna. Outro exemplo do Estado enquanto necessário sujeito passivo de direitos fundamentais decorre da disposição contida neste mesmo artigo, agora no 
inciso LXXV, segundo a qual aqueles que sofrerem erro judiciário ou ficarem presos além do tempo fixado na sentença, serão indenizados pelo Estado. (MENDES, COELHO e BRANCO, 2010)

Sendo assim, é possível perceber que a irradiação dos efeitos das normas e valores constitucionais tem como um de seus principais aspectos a eficácia dos direitos fundamentais nas relações jurídicas. Considerando que a garantia de direitos fundamentais é um dos objetivos do constitucionalismo - e não deixando de perceber que o legislador constituinte pátrio introduziu em nossa Carta Maior um amplo rol de direitos e garantias fundamentais - constatase que a constitucionalização do direito deverá resultar na observância daqueles em quaisquer relações travadas em nosso ordenamento jurídico, sejam elas verticais ou horizontais.

\section{POSSIBILIDADE DE APLICAÇÃO DE DIREITOS FUNDAMENTAIS NAS RELAÇÕES PRIVADAS}

Tradicionalmente, os direitos fundamentais foram concebidos para serem exercidos nas relações que vinculavam particulares ao Estado, considerando que aqueles eram frágeis e hipossuficientes perante este. Em outras palavras, o Poder Público era apontado como o único sujeito passivo dos direitos fundamentais na época de sua consagração.

A limitação do destinatário de tais direitos a somente este sujeito está relacionada à própria finalidade que motivou sua criação: imunizar o indivíduo perante os poderes estatais. O Estado era visto, sobretudo até antes das crises sociais e econômicas do século XX, como um vilão dos direitos individuais (MENDES, COELHO e BRANCO, 2010). Destarte, a consagração de direitos fundamentais visava proteger os particulares das ameaças que sofriam em sua esfera individual, acreditando-se que a origem de tais ameaças eram tão somente atuações do Poder Público.

Contudo, rapidamente ficou demonstrada a insuficiência desta visão limitada. A eclosão de crises sociais e econômicas levou à constatação de que o Estado deveria tomar providências para que a sociedade civil não destruísse a si própria. Sendo assim, o Poder Público deixava de ser visto como um vilão dos direitos individuais para ser enxergado como um agente capaz de evitar que a sociedade civil se autodeteriorasse, garantindo que todos pudessem gozar de efetiva liberdade. Conforme aponta Leonel (2014, p. 06), a falha desta visão é claramente apontada pela concepção do liberalismo, demonstrando que em uma 
relação privada, o contratante mais poderoso tende a dominar o mais fraco, podendo violar seus direitos fundamentais.

Destarte, deixou de fazer sentido a premissa de que os direitos fundamentais somente devem ser aplicados nas relações entre o Estado e particulares, marcadamente verticais. Somada à constatação de que os poderes públicos não eram mais considerados a única fonte de ameaça aos particulares, mas também instrumentos que poderiam garantir aos cidadãos condições de liberdade, tornou-se mais clara a percepção de que muitas vezes as ameaças aos particulares provinham de outros particulares, e não do Estado. Em outras palavras, várias são as situações em que os direitos fundamentais são violados de forma mais enfática pelos poderes econômico-sociais do que propriamente pelo Estado (PÉREZ LUÑO, 1995, p. 314).

Neste sentido, destaca Miranda:

\footnotetext{
Não se compreenderiam uma sociedade e uma ordem jurídica em que o respeito da dignidade e da autonomia da pessoa fosse procurado apenas nas relações com o Estado e deixasse de o ser nas relações das pessoas entre si. Não basta, pois, limitar o poder político: é preciso também assegurar o respeito das liberdades de cada pessoa pelas demais pessoas. (2000, p. 325)
}

Sendo assim, a atuação estatal deixou de ser vista como a única fonte de agressões aos direitos fundamentais. A insuficiência de tal visão fez com que cedesse seu lugar à percepção de que ao Estado não cabia apenas não violá-los, mas também contribuir para que não fossem violados (DUQUE, 2013, p. 62)

Sobretudo em países democráticos, caracterizados por adotarem um regime político no qual o poder pertence ao povo e onde todos merecem participar igualmente das decisões acerca dos rumos da nação, fica evidente que nem sempre o Poder Público significa a maior ameaça aos particulares (SILVA, 2005, p. 17). Outros particulares, especialmente os que detêm o poder social e econômico, ou ainda poder político de peso, trazem para os sujeitos privados constrangimentos que se buscavam prevenir nas suas relações com o Estado.

Sendo assim, outras forças sociais, baseadas em atuações privadas, demonstram que os motivos que levaram à proclamação dos direitos fundamentais também se encontram presentes nas relações que vinculam particulares a outros particulares. Considerando que tais direitos foram consagrados com o propósito de evitar e combater ameaças aos direitos individuais, merecem ser aplicados nas relações entre particulares, tendo em vista que elas também oferecem riscos para tal categoria de direitos.

Ademais, a introdução de direitos fundamentais no documento constitucional implica dizer que todas as relações sociais reguladas por normas que façam parte deste ordenamento 
jurídico devem encontrar nos valores constitucionais seus fundamentos de validade. A irradiação dos efeitos das normas e valores da constituição não foi condicionada a determinadas relações, devendo sua concretização ser efetivada tanto nas relações horizontais, quanto nas verticais.

Sendo assim, demonstrando a relação entre a normatividade da constituição e a aplicação de direitos fundamentais entre particulares, destaca Pereira (2006, p. 185) que "a concepção de que os direitos fundamentais incidem diretamente nas relações privadas é uma consequência natural e lógica da adoção de um modelo hermenêutico comprometido com o caráter normativo da constituição".

No mesmo sentido, Mendes, Coelho e Branco reforçam que a força vinculante, a eficácia imediata dos direitos fundamentais e seu posicionamento no topo da hierarquia das normas jurídicas orientam que não existem óbices à aplicação de tais direitos em relações privadas:

\begin{abstract}
A percepção clara da força vinculante e da eficácia imediata dos direitos fundamentais e da sua posição no topo da hierarquia das normas jurídicas reforçou a ideia de que os princípios que informam os direitos fundamentais não poderiam deixar de ter aplicação também no setor do direito privado. (2010, p. 353)
\end{abstract}

Neste ponto, interessante é perceber a feição objetiva dos direitos fundamentais, relativa à consagração da segunda geração destes direitos. Como acima já mencionado, foi reconhecida ao Estado a atribuição de garantir condições que possibilitassem à sociedade civil a plena liberdade.

Destarte, oportunas são as palavras de Novais (2006, p. 34), que ao buscar inspiração em Dworkin, afirma que a possibilidade de ser detentor de um direito fundamental significa ter um trunfo contra o Estado, ou ainda contra a maioria. Mesmo que aquele não viole direito fundamental, tem a obrigação de evitar que cidadãos (ou pessoas jurídicas que os titulem) tenham seus direitos fundamentais violados por outrem.

Sendo assim, percebe-se que com a introdução de direitos fundamentais na Carta Maior, e com o consequente processo de constitucionalização, os poderes públicos não somente passam a ter a atribuição de respeitar os direitos fundamentais, mas também de fazê- los respeitados pelos indivíduos (MENDES, COELHO e BRANCO, 2010). Daí decorre o aspecto objetivo dos direitos fundamentais, o qual se refere à noção de que expressam os valores que estruturam a ordem jurídica e social, devendo ser valorizados em todos os setores da vida civil, além de promovidos pelo Estado como princípios que orientam a sociedade. 
Acerca da passagem da dimensão subjetiva da tradição liberal para uma dimensão objetiva dos direitos fundamentais, Vale (2004, p. 72) destaca os direitos fundamentais devem ser aplicados em quaisquer relações que vinculem particulares, independentemente das partes estarem em posição de igualdade. De acordo com o autor, o paralelo que pode ser feito entre o Estado e grandes corporações é apenas um dos passos iniciais para a compreensão de que, necessariamente, direitos fundamentais não são violados apenas pela atuação estatal.

Neste mesmo sentido, destaca Sarmento sobre a conotação objetiva dos direitos fundamentais:

\begin{abstract}
No mesmo diapasão, afirma-se que a dimensão objetiva expande os direitos fundamentais para o âmbito das relações privadas, permitindo que estes transcendam o domínio das relações entre cidadão e Estado, às quais estavam confinados pela teoria liberal clássica. Reconhece-se então que tais direitos limitam a autonomia dos atores privados e protegem a pessoa humana da opressão exercida pelos poderes sociais não estatais, difusamente presentes na sociedade contemporânea. (2006, p. 197)
\end{abstract}

Como decorrência de tais concepções, consolidou-se a doutrina de que pessoas privadas também podem ser sujeitos passivos de direitos fundamentais. A eficácia horizontal destes direitos, como ficou conhecida sua incidência nas relações entre particulares, sobretudo a partir dos anos cinquenta, passou a fazer parte do mundo jurídico como evidência clara do processo de constitucionalização.

\title{
5 ESTÁGIO DA DOUTRINA CONSTITUCIONAL DE OUTROS PAÍSES SOBRE A HORIZONTALIDADE DOS DIREITOS FUNDAMENTAIS
}

Fora do nosso Brasil, especificamente na Alemanha, Espanha, Itália, Israel, África do Sul e Portugal, a doutrina constitucional acerca da aplicação dos direitos fundamentais nas relações entre particulares está em estágio avançado. Este é um reflexo, sobretudo, da maturação da consciência destes países acerca da evidência da constitucionalização e da assimilação de que uma de suas principais decorrências é a irradiação de direitos fundamentais sobre todas as relações jurídicas.

Nestes países, primeiramente é dispensado ao documento constitucional o reconhecimento de que esta é a lei mais importante do ordenamento jurídico. Em decorrência, é consagrada a premissa de que suas normas e valores devem irradiar sobre todas as relações por ele regidas, inclusive as que tenham como partes apenas sujeitos particulares. Como resultado de tais assimilações, estes Estados percebem a necessidade de aprofundar seus 
estudos acerca da horizontalidade dos direitos fundamentais, sobretudo devido à importância que representa na vida do seu povo.

A Alemanha é o país onde o assunto é estudado sistematicamente há mais tempo. Além disso, foi neste Estado onde aconteceu um episódio que marcou a afirmação de que os direitos fundamentais também devem ser aplicados entre particulares: o caso Lüth. Este foi um dos casos mais significativos do constitucionalismo alemão no pós-guerra, uma vez que ocorreu em 1958.

Quanto à sua narrativa, destaca-se que teve sua origem na veiculação de um filme romântico, intitulado "Amada Imortal” e produzido pelo alemão Veit Harlan. Considerando que este produtor já tinha sido responsável por outros filmes, nos quais divulgava ideias nazistas, Eric Lüth, judeu que presidia o Clube da Imprensa, boicotou o referido filme romântico, com o apoio de outros judeus que gozavam de prestígio e influência na Alemanha (LEONEL, 2014).

Contudo, Harlan e os empresários que investiram no filme fracassado ajuizaram demanda judicial, alegando que a atitude de Lüth lhes causou prejuízos e, em conformidade com o Código Civil alemão, seu ato danoso merecia ser reparado. Na instância ordinária, o pleito de Harlan foi atendido, gerando a inconformidade de Lüth, que recorreu da decisão, sob o fundamento de que a Constituição alemã garantia a liberdade de expressão. Como resultado do episódio, a Corte Constitucional alemã desenvolveu importantes conceitos relativos à teoria dos direitos fundamentais, tais como a sua eficácia horizontal, a dimensão objetiva dos direitos fundamentais e a necessidade de ponderação, diante de situações onde ocorra a colisão de direitos (LIMA, 2008).

Considerando na Alemanha o desenvolvimento da doutrina constitucional é o mais avançado do mundo, convém analisar os fatores que o influenciam.

Observando o conteúdo da Constituição alemã, notadamente o rol de direitos fundamentais que apresenta, percebe-se que não prevê uma vasta quantidade de tais direitos (SILVA, 2005). Comparando-a com nossa Constituição, embora reconhecendo que o documento constitucional brasileiro apresenta um extenso catálogo de direitos fundamentais, fica claro que é reduzido o conjunto de direitos fundamentais consagrados no documento alemão, ainda que preveja direitos não reconhecidos pela nossa Constituição.

Além disso, é possível constatar que na Alemanha existe um antagonismo muito marcante entre jurisdição ordinária e jurisdição constitucional. Neste país, normas que pertencem ao plano constitucional são extremamente valorizadas perante as normas que 
compõem o plano infraconstitucional, sendo estas últimas consideradas desprovidas de valor significativo, caso conflitem com aquelas (SCHUPPERT; BUMKE, 2000).

Anotadas tais constatações acerca do ordenamento jurídico alemão, é possível chegar a algumas conclusões relativas aos motivos que favorecem a assimilação da doutrina da horizontalidade dos direitos fundamentais naquele país. Tais conclusões contribuem para traçar um perfil dos ornamentos jurídicos favoráveis à maturação dos estudos acerca da eficácia horizontal dos direitos fundamentais.

Considerando que o documento constitucional alemão não conta com um vasto rol de direitos fundamentais, o estudo intenso do tema supre lacunas que porventura surjam na aplicação e extensão de tais direitos às relações entre particulares. Assimilando o sentido dos direitos fundamentais previstos, o desenvolvimento da doutrina constitucional acerca do assunto pode deixar claro como deverão ser aplicados tais direitos nas relações particulares, notadamente quando a limitação de sua previsão constitucional torna obscura a possibilidade de aplicá-los, bem como a maneira como isto poderá ocorrer.

Além disso, uma rigorosa separação entre os planos constitucional e infraconstitucional tenderia a configurar um ordenamento jurídico onde o campo mais forte (o constitucional) exerceria uma influência maior sobre o de menor força (o infraconstitucional). Diante de uma irradiação mais intensa dos efeitos do plano constitucional sobre o infraconstitucional, existiria um estímulo maior ao desenvolvimento de uma teoria acerca do fenômeno, tendo em vista que sua repercussão prática seria de indiscutível alcance e relevância nas relações sociais regidas por tal ordenamento jurídico.

Ainda que a doutrina dos Estados Unidos acerca da eficácia horizontal dos direitos fundamentais não seja tão desenvolvida como a da Alemanha ou dos demais países acima mencionados, também merece algumas considerações. Embora se dediquem ao tema de forma assistemática, há muito tempo a doutrina e a jurisprudência norte americanas se detêm sobre a incidência de direitos fundamentais entre particulares (LEONEL, 2014).

Um dos fatos mais interessantes relacionados ao desenvolvimento do assunto neste país foi o seu marco inicial. Trata-se da decisão proferida no caso Shelley v. Kraemer, o qual claramente levantava a discussão acerca da possibilidade de aplicação de direitos fundamentais em relações que vinculavam pessoas privadas (SILVA, 2005).

Como narra Silva (2005), este caso surgiu a partir de uma cláusula contratual estabelecida por um loteamento da cidade de Saint Louis, a qual proibia que os compradores de terrenos no local os alienassem a indivíduos que não fossem brancos. Contudo, um dos 
proprietários vendeu sua propriedade a um casal de negros e o caso foi posto à apreciação da justiça, pois a venda foi contestada judicialmente com base na disposição contratual restritiva.

Quanto ao julgamento do caso, o Tribunal Estadual de Missouri foi favorável à concretização da venda, mas recorreu-se da decisão e o caso passou à apreciação da Suprema Corte americana. Apreciando a contenda, este órgão entendeu que a Emenda XIV da Constituição americana - a qual pregava a igualdade - não deveria ser fundamento de validade do contrato relativo ao loteamento, pois acreditava que cláusulas contratuais decididas entre particulares eram fruto do exercício de sua autonomia privada, e a referida emenda somente merecia ser aplicada para regular ações estatais.

Provando não temer estar ferindo direitos fundamentais de particulares, notadamente o direito à igualdade, a Suprema Corte trouxe claramente em sua decisão final trecho afirmando que a Emenda XIV da Constituição americana não conferia nenhuma proteção a condutas meramente privadas, ainda que estas fossem discriminatórias. Eis o marco inicial do estudo da horizontalidade dos direitos fundamentais nos Estados Unidos.

Evidentemente, seus resultados não foram aqueles que o nível de maturidade hoje alcançado pela doutrina constitucional sobre o tema consideraria satisfatórios. Contudo, ainda que os Estados Unidos tenham iniciado suas discussões sobre o assunto se posicionando indubitavelmente contra a validade dos direitos fundamentais em relações entre particulares, este foi o pontapé inicial para discussões mais aprofundadas no país, bem como contribuiu para os estudos de outros Estados, que lhe tomou como exemplo a ser analisado.

Entretanto, não apenas os Estados Unidos e a Alemanha merecem destaque, dentre o rol de países que contam com estudos avançados acerca da horizontalização dos direitos fundamentais, como acima afirmado. Apenas reiterando o já exposto, a Espanha, a Itália, a África do Sul, Israel e Portugal também se sobressaem neste sentido (SOMBRA, 2011).

Em suma, são poucos os países em que se pode notar uma avançada doutrina constitucional acerca da eficácia horizontal dos direitos fundamentais. Apesar disso, também é possível constatar que outros países já contam com estudos bastante desenvolvidos acerca do tema, repercutindo nas suas doutrinas e jurisprudências.

Destarte, percebe-se que o assunto está gradativamente recebendo dos Estados a atenção que merece. Considerando que a estrutura dos ordenamentos jurídicos interfere na constitucionalização, e consequentemente no reconhecimento da incidência de direitos fundamentais entre particulares, a maturação dos estudos acerca do tema está contribuindo para que os diversos países do mundo driblem as dificuldades que seus sistemas jurídicos 
impõem à ampla eficácia de tais direitos e consolidem suas doutrinas e jurisprudências a assimilando.

\section{ESTÁGIO DA DOUTRINA CONSTITUCIONAL BRASILEIRA ACERCA DA APLICAÇÃO DE DIREITOS FUNDAMENTAIS EM RELAÇÕES PRIVADAS}

No nosso país, a doutrina constitucional da horizontalização dos direitos fundamentais ainda é pouco desenvolvida. Mesmo contando com um vasto rol de direitos fundamentais inseridos na Constituição - seja de forma explícita, notadamente no seu Título II, ou mesmo implicitamente - percebe-se que o Brasil não dispensa ao assunto a atenção que ele merece.

Embora seja possível constatar que a doutrina constitucional brasileira se dedica demasiadamente aos direitos fundamentais de cunho liberal, os quais fazem parte da primeira dimensão desta categoria de direitos, este não é o motivo que justifica seu estágio pouco avançado. Mesmo na análise dos direitos fundamentais que compõem as demais dimensões, o foco é exclusivamente na sua aplicação em relações verticais, as quais envolvem o Estado e particulares (SILVA, 2005).

Sendo assim, necessário se faz compreender um pouco acerca da evolução da constitucionalização no Brasil, para que a partir daí fique mais clara a compreensão acerca do baixo desenvolvimento de sua doutrina constitucional sobre a horizontalização.

O Brasil é um país de democratização tardia, assim como Portugal e Espanha, o que contribuiu para que a constitucionalização do direito se desenvolvesse recentemente, ainda que de maneira intensa. Ocorreu entre nós o mesmo movimento translativo experimentado pela Alemanha e pela Itália, qual seja, a passagem do documento constitucional para o centro do sistema jurídico (BARROSO, 2005).

Iniciando em 1988 e ganhando força nos últimos quinze ou vinte anos, somou-se à supremacia formal, da qual já gozava a Constituição brasileira, uma supremacia material, que segundo Barroso (2005, p. 2) fora "potencializada pela abertura do sistema jurídico e pela normatividade de seus princípios". Destarte, ocorreu o processo de "descodificação do direito civil", tendo em vista que a Carta Magna passou a ocupar o centro do sistema jurídico, antes ocupado pelo Direito Civil, exibindo uma poderosa força normativa.

Ainda que a Constituição tenha se consolidado no país como a fonte de validade de todas as normas do ordenamento, há que se considerar que a necessária reinterpretação dos institutos jurídicos sob a lente constitucional aconteceu em um passado recente. Sendo assim, 
justifica-se o baixo grau de desenvolvimento da doutrina constitucional acerca da irradiação dos efeitos dos valores constitucionais, inclusive os relativos aos direitos fundamentais (SILVA, 2005).

A aplicação de tais direitos, sobretudo em relações entre particulares, deve ser estudada cuidadosamente no Brasil, tendo em vista seu interesse prático na vida dos brasileiros. Neste ponto, convém esclarecer que a escassa doutrina pátria acerca do assunto, além de não implicar dizer que existem dúvidas acerca da possibilidade de particulares serem destinatários de direitos fundamentais, não dá margem ao entendimento de que é desnecessário o estudo da eficácia horizontal dos direitos fundamentais no Brasil.

Considerando que o art. 5 XVII, da Constituição Federal de 1988 veda expressamente quaisquer formas de discriminação no Brasil, um argumento bastante simplista poderia desvalorizar o estudo brasileiro sobre a aplicação de direitos fundamentais entre particulares. Contudo, ainda que condutas discriminatórias sejam expressamente vedadas no nosso país, é necessário que nossa pátria conte com um estudo sistemático acerca do tema.

Demonstrando tal necessidade, percebe-se que frequentemente nos deparamos com situações potencialmente discriminatórias, mas sequer refletimos sobre sua constitucionalidade. Exemplifiquemos com a reflexão acerca da avença firmada entre um ator famoso e a emissora de televisão para a qual trabalha, proibindo que o artista dê entrevistas ou apareça de qualquer forma em outras emissoras. Além dessa, também consideremos a situação em que o proprietário de uma loja que venda artigos japoneses limita seu quadro de funcionários a pessoas de origem japonesa.

Incrementando a certeza de que é necessária a discussão no Brasil, atente-se para a irrenunciabilidade e a inegociabilidade dos direitos fundamentais. Contratualmente ou não, muitos atos que fazem parte da vida cotidiana dos brasileiros, assim como das pessoas dos outros países, acarretam renúncia ao exercício de alguns direitos fundamentais, mesmo que temporariamente. Seriam, entre outros, os casos dos reality shows, que embora suscitem dúvidas acerca da violação da dignidade dos participantes, certamente violam, por decorrência de ato de vontade destes, sua privacidade, ainda que o art. $5^{\circ}, \mathrm{X}$, da Constituição Federal a considere inviolável (SILVA, 2005).

Destarte, resta evidente a imprescindibilidade de uma doutrina constitucional brasileira sobre a aplicação dos direitos fundamentais em relações sociais. Ainda que nos últimos anos se tenha assistido ao seu maior desenvolvimento, continua bastante escassa e merecendo detida atenção por parte da doutrina e jurisprudência pátrias. 


\section{MODELOS DE RELAÇÃO ENTRE DIREITOS FUNDAMENTAIS E RELAÇÕES ENTRE PARTICULARES}

Nos países onde o tema da eficácia horizontal dos direitos fundamentais é estudado de forma mais sistemática, são apontados dois modelos de aplicação e formas de produção de efeitos: modelo de efeitos diretos e modelo de efeitos indiretos. Além destes, são mencionados mais dois, considerados alternativos: um modelo que recusa qualquer efeito aos direitos fundamentais fora da relação cidadão-Estado e um modelo que acredita na imputação das ações particulares ao Estado ou na equiparação da atuação particular à estatal.

O modelo de efeitos diretos segue o fundamento de que assim como os direitos fundamentais têm aplicabilidade direta nas relações entre o Estado e os cidadãos, da mesma forma também terão nas relações que envolvem somente particulares. Destarte, tal modelo prega que não seria necessária nenhuma ação intermediária para sua incidência em relações privadas (SILVA, 2005).

Contudo, este modelo merece algumas críticas, as quais repercutem na sua aceitação amplamente minoritária nos Estados que discutem sistematicamente o assunto. Sendo a aplicação dos direitos fundamentais entre particulares feita sem qualquer intermediação, ainda que legislativa, é dificultada a relação entre os diferentes ramos do direito, especialmente a sobrevivência da autonomia privada, emanada do direito civil. Além disso, pode resultar na perda de clareza dos conceitos que fazem parte do direito privado (SOMBRA, 2011).

Já o modelo de efeitos indiretos visa impedir que o direito constitucional tenha total domínio sobre o direito privado, o que defende que ocorreria caso os direitos fundamentais tivessem efeito absoluto nas relações particulares. Sendo assim, este modelo reconhece a existência de um direito geral de liberdade, presente na imensa maioria das constituições das democracias do ocidente (SILVA, 2005).

Explicando como seria tal direito, o modelo dos efeitos indiretos prega que aquele também incluiria a liberdade, que no caso seria a de os cidadãos participantes de uma relação civil contornarem as disposições de direitos fundamentais, necessariamente aplicáveis às relações verticais. Desta forma, a liberdade contratual se manteria preservada.

Todavia, também este modelo pode ser criticado, ainda que seja o mais aceito em quase todos os países que estudam o tema sistematicamente. Por acreditar que os direitos fundamentais não são somente garantias dos indivíduos perante o Estado, mas também uma ordem objetiva de valores que passa a fazer parte do direito privado, especialmente através das cláusulas gerais, pode ser criticado pela incerteza da existência uma ordem ou sistema de 
valores. Além disso, é alvo de críticas por não haver a garantia de que participando das relações entre particulares apenas por meio das cláusulas gerais, os direitos fundamentais e seus efeitos serão eficazmente tutelados. Por fim, o modelo dos efeitos indiretos ainda é criticado com bases jurisdicionais, tendo em vista que a autonomia do direito privado é ameaçada por uma possível dominação do órgão guardião da constituição sobre o plano infraconstitucional.

Quanto ao modelo que nega efeitos aos direitos fundamentais fora das relações que vinculam o Estado a particulares, pode ser entendido como um modelo que não acredita que os direitos fundamentais exercem influência nas relações privadas. Destarte, está relacionado à função essencial destes direitos, por muitos chamada de clássica: proteger os indivíduos contra ameaças dos Poderes Públicos. A radicalização e absolutização que os defensores desse modelo fazem acerca da importância dos direitos fundamentais repercutem em sua refutação, tendo em vista a impossibilidade destes direitos não serem estendidos às relações particulares.

Em relação ao modelo que imputa ao Estado a responsabilidade por atos privados ou os equipara aos atos estatais, está relacionado à concepção liberal de direitos fundamentais, que implica na sua aplicação apenas nas relações das quais o Estado participa. A doutrina da state action, desenvolvida nos Estados Unidos, está associada a este modelo, pregando, da mesma forma que argumentam seus defensores, que só existiria violação a direitos fundamentais por meio de ação estatal; contudo, muitas das vezes atos privados se igualariam a atos estatais, quando violassem direitos fundamentais. Neste sentido, destaca Silva:

Ao invés de negar a aplicabilidade dos direitos fundamentais às relações privadas, a doutrina da state action tem como objetivo justamente definir em que situações uma conduta privada está vinculada às disposições de direitos fundamentais. (2005, p. 99)

Além disso, a teoria do state action também encontra certo fundamento na insuficiência da dicotomia entre ação estatal e ação privada, conforme demonstra Zippelius:

\begin{abstract}
A contraposição não-diferenciada entre ações estatais e ações puramente privadas (...) é uma simplificação exagerada: em uma sociedade plural, formam-se, nos espaços deixados à autonomia privada, instituições da vida econômica, empresas dos meios de comunicação e outras "forças sociais", que desempenham importantes funções na vida social e que alcançam posições de poder, por força das quais podem influir de forma prejudicial no sistema político. (1994, p. 251)
\end{abstract}

Observados tais modelos apresentados, fica mais clara a percepção de que relações privadas também são espaços para que os direitos fundamentais sejam aplicados. Analisadas 
suas principais características e motivos pelos quais são criticados, é evidente que os particulares que fazem parte de relações privadas também estão sendo ameaçados e devem ser amparados por direitos fundamentais, da mesma forma que merecem ao se relacionarem com o Estado.

\section{CONSTITUCIONALIZAÇÃO E JUDICIALIZAÇÃO DAS RELAÇÕES SOCIAIS NO BRASIL}

Considerando que a constitucionalização, como já esclarecida, diz respeito à irradiação dos valores constitucionais aos demais ramos do ordenamento jurídico, é relevante compreender que esta difusão da Carta Magna ocorre por meio da jurisdição constitucional. Observando a atuação dos diferentes atores da constitucionalização, percebe-se que este processo é efetivado por meio da aplicação direta da constituição, da declaração de inconstitucionalidade de normas que lhe são incompatíveis e mesmo da interpretação conforme a constituição.

Contudo, percebe-se que outro fenômeno atua ao lado da constitucionalização, expandindo os efeitos dos valores constitucionais. Trata-se da judicialização, fenômeno que ganhou vitalidade com a promulgação da Constituição Federal de 1988, sobretudo devido à intensificação da demanda social por justiça. Quanto aos motivos que estimularam essa intensificação, destacam-se três: a redescoberta da cidadania, a conscientização das pessoas acerca dos seus próprios direitos e a circunstância de o documento constitucional escrito do país criar novos direitos, introduzir novas ações e ampliar a legitimação ativa para tutelar interesses (BARROSO, 2005).

Como consequência das reivindicações sociais por mais justiça, o Brasil assistiu a uma forte ascensão institucional do Poder Judiciário nos últimos anos, evidenciada através da maior importância dispensada pela coletividade ao papel desempenhado pelos juízes e tribunais. Tendo sido recuperadas as liberdades democráticas e as garantias da magistratura, os juízes e tribunais passaram a desempenhar uma atribuição política - ao lado dos poderes Legislativo e Executivo - e deixaram de serem vistos como departamentos especializados tecnicamente.

Nessa perspectiva aqui sustentada, entendo que o Poder Judiciário (aqui entendido como justiça constitucional) deve ter uma nova inserção no âmbito das relações dos poderes de Estado, levando-o a transcender as funções de checks and balances, mediante uma atuação que leve em conta a perspectiva de que os valores constitucionais têm precedência mesmo contra textos legislativos produzidos por 
maiorias parlamentares (que, a toda evidência, devem obediência à Constituição). (STRECK, 2003, p. 28)

Em meio às mudanças que vinham ocorrendo na forma de enxergar o papel do Poder Judiciário, não tinha como as relações entre a sociedade e as instituições judiciais não serem afetadas. Em vista disso, deve-se observar que houve uma modificação substantiva de tais relações, resultando em reformas estruturais e gerando discussões complexas acerca da extensão dos poderes das instituições judiciais.

Pois bem: em razão desse conjunto de fatores - constitucionalização, aumento da demanda por justiça e ascensão institucional do Judiciário -, verificou-se no Brasil uma expressiva judicialização de questões políticas e sociais, que passaram a ter nos tribunais a sua instância decisória final. (BARROSO, 2005, p. 03)

O processo de judicialização, ainda que possa trazer resultados semelhantes à constitucionalização (fenômeno que indiscutivelmente goza de legitimidade e valorização por aqueles que assimilam a importância da constituição), recentemente tem despertado na doutrina brasileira discussões acerca de sua legitimidade, bem como das possibilidades e limites da função judicial.

A essência dos debates gravita em torno das relações entre o constitucionalismo e a democracia, especialmente quanto às tensões e superposições entre eles. $\mathrm{O}$ regime democrático não pode ser resumido ao governo da maioria, tendo em vista que sua lógica está inspirada em valores, mas certamente o processo político majoritário inspira-se em interesses.

Sendo assim, são necessários mecanismos que preservem os valores da lógica democrática, o que muitas vezes resulta na atribuição da responsabilidade de preservá-los ao Poder Judiciário. Destarte, o papel deste, e também dos tribunais supremos e constitucionais, é o de tutelar o regime democrático e, especialmente, promover os valores constitucionais. Em outras palavras, sem que desqualifique sua atuação, o Judiciário deve prezar para que seja garantida a estabilidade constitucional, sobretudo ao analisar conflitos entre os demais Poderes, entre estes e particulares, ou ainda, conflitos privados (BARROSO, 2005).

A judicialização das relações sociais é, pois, um fenômeno que deve ser estudado com bastante cautela, considerando a dificuldade para que seja encontrado o ponto de equilíbrio entre a interpretação dos valores constitucionais pelo Poder Judiciário e o sistema político majoritário. Ainda que a prolixidade do texto constitucional, a disfuncionalidade do Judiciário e a falta de legitimidade dos outros Poderes dificultem ainda mais o processo de judicialização, a atuação conjunta dos atores da constitucionalização, gradativamente 
permitirá que as instituições brasileiras contribuam para a efetivação dos valores constitucionais nas relações jurídicas, especialmente para que sejam aplicados direitos fundamentais em relações privadas.

\section{CONCLUSÃO}

As relações jurídicas horizontais - marcadas pela posição de igualdade entre as partes que delas participam - oferecem riscos significativos aos direitos fundamentais dos homens. Neste sentido, a ideia de que o Estado é o principal sujeito passivo das normas de direitos fundamentais se tornou ultrapassada, diante do reconhecimento de que são nas relações privadas onde deve haver maior proteção destes direitos.

Neste sentido, o processo de constitucionalização se revela como um importante mecanismo para garantir que os direitos fundamentais também serão aplicados em relações privadas, caracterizadas por vincular unicamente sujeitos particulares. Contudo, saliente-se que a atuação estatal também pode ser observada nestas relações, não através da manifestação do Estado como parte, mas como entidade que atua no sentido de garantir que os particulares tenham seus direitos fundamentais respeitados.

Destarte, constata-se que houve uma modificação na visão tradicional dos destinatários das normas de direitos fundamentais, defendida no momento de sua consagração. Enquanto estes foram tradicionalmente concebidos para proteger os particulares frente ao Estado, então considerado a grande ameaça à esfera individual do homem, logo mais se tornaram instrumentos que necessariamente deveriam ser observados nas relações privadas, tendo em vista que foi reconhecido que eram dos próprios particulares que provinham as maiores ameaças aos direitos individuais.

Sendo assim, constata-se o quanto o processo de constitucionalização do direito contribui para que os sujeitos particulares possam fazer parte de relações privadas, tendo a certeza de que seus direitos fundamentais estarão sendo protegidos.

A irradiação dos princípios e valores constitucionais relacionados aos direitos fundamentais é a principal responsável pela assimilação de que todo o ordenamento jurídico deve garantir que as relações privadas também serão espaço propício à concretização destes. Considerando que a Constituição do Estado é sua lei maior, e de onde todo o sistema jurídico do país deve retirar seu fundamento de validade, conclui-se que a valorização dos direitos fundamentais, feita pela Carta Magna, deve ser seguida em todos âmbitos que estão sob sua égide, especialmente naqueles que suscitam sua maior atenção. Portanto, somente resta 
concluir que as relações privadas, além de merecerem, clamam pela aplicação dos direitos fundamentais, a qual se revela como uma evidência da constitucionalização.

\section{REFERÊNCIAS}

BALDEZ, Paulo de Oliveira. A Imprescindibilidade do Uso da Constituição na Efetiva e Justa Solução dos Litígios. Rio de Janeiro: Lumen Juris, 2003.

BARROSO, Luís Roberto. Neoconstitucionalismo e constitucionalização do direito. Disponível em: <http://www.luisrobertobarroso.com.br/wpcontent/themes/LRB/pdf/neoconstitucionalismo_e_constitucionalizacao_do_direito_pt.pdf> Acesso em: 23 jul. 2015.

CANOTILHO, José Gomes. Direito constitucional e teoria da Constituição. Coimbra: Almedina, 1998.

DUQUE, Marcelo Schenk. Direito Privado e Constituição; Drittwirkung dos direitos fundamentais; Construção de um modelo de convergência à luz dos contratos de consumo. São Paulo: Revista dos Tribunais, 2013.

DURIG, Gunter. Direitos fundamentais e jurisdição civil. Trad. Luís Afonso Heck. In: HECK, Luís Afonso. Direitos fundamentais e direito privado: textos clássicos. Porto Alegre: Sergio Antonio Fabris Editor, 2012.

HESSE, Konrad. Concepto y cualidade de la Constitución. In: Escritos de derecho constitucional. Madrid: Centro de Estudos Políticos y Constitucionales, 1992

LEONEL, Ana Letícia Anarelli Rosati. Eficácia dos direitos fundamentais nas relações privadas: constitucionalizando o contrato na socialização do direito. Disponível em: <http://publicadireito.com.br/artigos/?cod=84d6700e5e27922b > Acesso em: 10 ago. 2015.

LIMA, George Marmelstein. 50 Anos do Caso Lüth: o caso mais importante da história do constitucionalismo alemão pós-guerra. s.l. 2008, Disponível em $<$ http://direitosfundamentais.net/2008/05/13/50-anos-do-caso-luth-o-caso-mais-importante-dahistoria-do-constitucionalismo-alemao-pos-guerra >. Acesso em: 15 ago. 2015.

MIRANDA, Jorge. Manual de Direito Constitucional: tomo IV: direitos fundamentais. $3^{\mathrm{a}}$ ed. Coimbra: Coimbra Editora, 2000.

MACHADO, Clara Cardoso. O Neoconstitucionalismo e a Aplicação Imediata dos Direitos Fundamentais nas Relações Privadas. Disponível em: <http://livros-erevistas.vlex.com.br/vid/neoconstitucionalismo-aplica-privadas-

75744834?_ga=1.142685622.2051396862.1438529426> Acesso em: 30 jul. 2015.

Rev. de Formas Consensuais de Solução de Conflitos | e-ISSN: 2525-9679 | Minas Gerais | v. 1 | n. 2 | p. 36 - 60 | Jul/Dez. 2015. 
MENDES, Gilmar Ferreira; COELHO, Inocêncio Mártires; BRANCO, Paulo Gustavo Gonet. Curso de Direito Constitucional. 5 Edição. São Paulo: Saraiva, 2010.

NIPPERDEY, Hans Carl. Direitos fundamentais e direito privado. Trad. Waldir Alves. In: HECK, Luís Afonso. Direitos fundamentais e direito privado: textos clássicos. Porto Alegre: Sergio Antonio Fabris Editor, 2012.

NOVAIS, Jorge Reis. Direitos fundamentais: trunfos contra a maioria. Coimbra: Coimbra, 2006.

PEREIRA, Jane Reis Gonçalves. Apontamentos sobre a Aplicação das Normas de Direito Fundamental das Relações Jurídicas Privadas entre Particulares. in BARROSO, Luís Roberto (org.). A nova Interpretação Constitucional: Ponderações, direitos fundamentais e relações privadas. 2.ed. Rio de Janeiro: Renovar, 2006.

PÉREZ LUÑO, Antonio Enrique. Derechos Humanos, Estado de Derecho y Constitucion. $5^{\mathrm{a}}$ ed. Madrid: Tecnos, 1995.

QUEIROZ, Ana Lúcia Soares; MAGALHÃES, Helen Pereira Cotrim. Aspectos positivos da Constitucionalização do Direito Civil. Disponível em: $<$ http://hellencotrim.jusbrasil.com.br/artigos/111892776/aspectos-positivos-daconstitucionalizacao-do-direito-civil> Acesso em: 23 jul. 2015.

SARLET, Ingo Wolfgang. A eficácia dos direitos fundamentais. Porto Alegre: Livraria do Advogado, 2012.

SARMENTO, Daniel. Direitos Fundamentais e Relações Privadas. 2a Edição. Rio de Janeiro: Lumen Júris, 2006.

A vinculação dos Particulares aos Direitos Fundamentais no Direito Comparado e no Brasil. in BARROSO, Luís Roberto (org.). A nova interpretação constitucional ponderação, direitos fundamentais e relações privadas. 2.ed. Rio de Janeiro: Renovar, 2006.

SCHUPPERT, Gunnar Folke; BUMKE, Christian. Die Konstitutuionalisierung der Rechtsrdnung: Überlegungen zum Verhältnis von verfassungsrechtlicher Ausstrahlungswirkung und Eigenständigkeit des "einfachen" Rechts. Baden-Baden: Nomos, 2000.

SILVA, Virgílio Afonso da. A constitucionalização do direito: os direitos fundamentais nas relações entre particulares. São Paulo: Malheiros Editores, 2005.

SOMBRA, Thiago Luís Santos. A eficácia dos direitos fundamentais nas relações privadas. São Paulo, Atlas, 2011. 
STRECK, Lenio Luiz. Hermenêutica e Concretização dos Direitos Fundamentais-Sociais no Brasil. Rio de Janeiro: Lumen Juris, 2003.

TEIXEIRA, Anderson Vichinkeski. Globalização, soberania relativizada e desconstitucionalização do direito. In: TEIXEIRA, Anderson Vichinkeski (org.). A constitucionalização do direito. Porto Alegre: Sergio Antonio Fabris, 2008.

TEPEDINO, Gustavo. Crise das fontes normativas e técnica legislativa na Parte Geral do Código Civil de 2002. In: Revista Forense. Separata. Vol. 364.

VALE, André Rufino do. Eficácia dos direitos fundamentais nas relações privadas. Porto Alegre: Sergio Antonio Fabris Editor, 2004.

ZIPPELIUS, Reinhold. Allgemeine Staatslehre. München: C. H. Beck, 1994. 